\title{
Prevalence of poor and rapid metabolizers of drugs metabolized by CYP2B6 in North Indian population residing in Indian national capital territory
}

\author{
Ekta Varshney ${ }^{1}$, Nilanjan Saha², Monika Tandon², Vikesh Shrivastava ${ }^{2}$ and Shakir Ali ${ }^{* *}$
}

\begin{abstract}
Identification of poor and rapid metabolizers for the category of drugs metabolized by cytochrome P450 2 B6 (CYP2B6) is important for understanding the differences in clinical responses of drugs metabolized by this enzyme. This study reports the prevalence of poor and rapid metabolizers in North Indian population residing in the National Capital Territory.

The prevalence of poor and rapid metabolizers was determined in the target population for the category of drugs metabolized by CYP2B6 by measuring plasma bupropion, a drug metabolized by CYP2B6, and its metabolite. Bupropion (75 mg) was administered to 107 volunteers, and the drug (bupropion) and its metabolite (hydroxybupropion) were determined simultaneously by LCMS/MS in the plasma. CYP2B6 activity was measured as hydroxybupropion/bupropion ratio, and volunteers were categorized as rapid or poor metabolizers on the basis of cutoff value of log (hydroxybupropion/bupropion). Significant differences were observed between the mean metabolite/drug ratio of rapid metabolizers (Mean $=0.59$ ) and poor metabolizers (Mean $=0.26)$ with $p<0.0001$. Results indicate that $20.56 \%$ individuals in the target population were poor metabolizers for the category of drugs metabolized by CYP2B6. Cutoff value defined in this study can be used as a tool for evaluating the status of CYP2B6 using bupropion as a probe drug. The baseline information would be clinically useful before administering the drugs metabolized by this isoform.
\end{abstract}

Keywords: Cytochrome P450, CYP2B6, Bupropion, Drug metabolism, LCMS/MS, India

\section{Introduction}

Human cytochrome P450 2B6 (CYP2B6) is involved in the biotransformation of a variety of clinically important drugs such as the antiretroviral nevirapine (NVP) and efavirenz (EFV), which are used to treat AIDS and/or stop the spread of HIV infection (Erickson et al. 1999; Ward et al. 2003), antimalarial drug artemisinin (Simonsson et al. 2003; Mehlotra et al. 2006) and other drugs including cyclophosphamide, tamoxifen, diazepam, and bupropion (Lang et al. 2001; Wang and Thompkins 2008). However, the rates with which these drugs are metabolized vary considerably in individual hepatic

\footnotetext{
* Correspondence: sali@jamiahamdard.ac.in

'Department of Biochemistry, Jamia Hamdard, Hamdard Nagar, New Delhi 110062, India

Full list of author information is available at the end of the article
}

microsomes, and this variation is believed to be caused by CYP2B6 isoforms, besides the environmental factors such as the enzyme inducers. Clinical importance of genetic variations and role of ethnicity of CYP2D6, CYP2C19, CYP2C9, and CYP2D6 are well known (Adithan et al. 2003; Anitha and Banerjee 2003; Kumar et al. 2010; Lamba et al. 1998a, b) but CYP2B6 has only recently been recognized to code for a highly variable enzyme of potential clinical importance (Lang et al. 2001; Lamba et al. 2003). More than 100 DNA variations have been reported in CYP2B6 gene, and many of them show extensive linkage disequilibrium giving rise to distinct haplotypes. The spectrum of functional consequences of these variations is wide and includes null alleles with no detectable function and/or expression (alleles CYP2B6*8, *12, "15, "18, *21), alleles with 
partially reduced function/expression (CYP2B6*5, *6, *7, *11, *14, *19, *20, *21) (Lamba et al. 2003; Klein) and alleles with increased expression (CYP2B6*22) (Zukunft et al. 2005).

Clinical relevance of $C Y P 2 B 6$ variation has been demonstrated for the anti-HIV drug efavirenz. Common clinical practice of administering the same dose to all patients leads to profound differences in drug plasma concentration, which is correlated with patient genotype (Tsuchiya et al. 2004; Novoa et al. 2005). Patients with high drug concentrations are at risk of developing concentration related central nervous system toxicity, including insomnia, fatigue, and headache, which often lead to discontinuation of therapy. Thus, for a drug such as efavirenz, dose adjustment based on CYP2B6 genotype could prevent administration of too-high doses, and increase the safety and efficacy of therapy. Further, CYP2B6 variant genotyping at baseline may allow clinicians to identify patients who are at risk of treatment failure or drug toxicity (Novoa et al. 2005; Ramachandran et al. 2009). Some of these variations are rare, but many are common, with allele frequencies between $10 \%$ and almost $50 \%$, depending on the population (Klein et al. 2005; Solus et al. 2004). Ethnic or racial interindividual CYP2B6 polymorphism in various populations has been reported in Caucasians (Lang et al. 2001), Japanese (Hiratsuka et al. 2002 and Hiratsuka et al. 2004), African-American-Hispanic (Lamba et al. 2003; Hesse et al. 2004), Korean (Cho et al. 2004), Mongolian (Davalkham et al. 2009), Spain (Novoa et al. 2005), and South Indians (Ramachandran et al. 2009), but not in North Indian population, and, hence, CYP2B6 was selected in this study.

\section{Aim of the study}

This study was aimed at to find out the prevalence of poor and rapid metabolizers for the category of drugs metabolized by CYP2B6 in the target population by measuring plasma bupropion, a drug metabolized by CYP2B6, and its metabolite.

\section{Method}

\section{Clinical study}

Study protocol and corresponding informed consent form (ICF) were reviewed by the Institutional Review Board, and procedures were in accordance with the Helsinki Declaration of 1975, as revised in 2000. Subjects were informed before initiation of the study through an oral presentation regarding the purpose of the study, procedures to be carried out, potential hazards and rights of the subjects. Subjects (170) were selected randomly from the volunteer bank of clinical pharmacology unit of Ranbaxy Laboratories Limited. The volunteer bank comprises of healthy volunteers from the Indian
National Capital Region (INCR), which includes the metropolitan area encompassing the entire national capital territory (Delhi) and urban areas of neighboring states of Haryana, Uttar Pradesh and Rajasthan. Subjects were selected on the basis of inclusion and exclusion criteria after obtaining written informed consent. Medical histories and demographic data were recorded. Each subject underwent physical examination and laboratory tests of hematology, hepatic and renal function. Hematological parameters were analyzed on fully automated five part differential count autoanalyzer, Sysmex XT 1800xi, procured from Transasia Co. The biochemical parameters, which included plasma glucose, serum blood urea nitrogen, serum creatinine, serum total bilirubin, serum alkaline phosphatase, serum alanine and aspartate aminotransferases, serum cholesterol, and urine drug of abuse, were analyzed on a fully automated biochemistry analyzer, Dimension Rxl (Seimens Diagnostics, USA), according to manufacturer's instruction. Urinalysis, routine and microscopic examination, was done by manual dipstick method (Multistick from Seimens Diagnostics). Rejection or selection of subjects was based on specific clinical and medical examination as shown in Table 1. Subjects were kept under medical supervision in the clinical pharmacology unit of Ranbaxy Laboratories Limited, New Delhi. Bupropion (Wellbutrin $^{\mathrm{R}}$, GlaxoSmithKline, USA) (75 mg) was administered orally to selected (107) volunteers along with $240 \mathrm{ml}$ of water under the supervision of a trained Medical Officer. The EDTA blood sample $(6 \mathrm{ml}$ each) was collected at 0 , $1,3,6$ and $10 \mathrm{~h}$ after drug administration. Number of volunteers was calculated statistically based on the prevalence of percentage poor metabolizers present worldwide. Sample size of 100 volunteers was calculated statistically. The prevalence of CYP2B6 in Indian population is $\sim 40 \%$, and therefore, a sample size of 100 subjects was calculated and found sufficient to estimate the prevalence with expected $95 \%$ binomial confidence

Table 1 Number of volunteers rejected on the basis of medical and clinical examination

\begin{tabular}{ll}
\hline Physical and medical examination & $\begin{array}{l}\text { Number of } \\
\text { volunteers }\end{array}$ \\
\hline ECG & 4 \\
\hline Medical Examination & 12 \\
\hline $\begin{array}{l}\text { Outliers in hemogram and } \\
\text { biochemical parameters }\end{array}$ & 11 \\
\hline Drug of Abuse positive & 18 \\
\hline Serology positive (HIV, HCV, HbsAg) & 6 \\
\hline Others & 12 \\
\hline Total (Rejected) & 63 \\
\hline Selected for phenotyping (Total - Rejected) & $170-63=107$ \\
\hline $\begin{array}{l}\text { A total number of } 170 \text { volunteers were screened and } 107 \text { were recruited for the } \\
\text { study. }\end{array}$
\end{tabular}


interval ranging 30 to $50 \%$. Based on the simulation with higher sample size (200 or 300), not much benefit was found in precision with a sample size of 100 subjects.

\section{Determination of bupropion and its metabolite by LCMS/MS}

CYP2B6 activity was determined by calculating hydroxybupropion/bupropion ratio in plasma by LCMC/MS on Waters Quattro premier mass spectrometer. Samples were analyzed using a set of calibration standards spiked in human plasma. Three levels of quality control samples were distributed through each batch of study samples assayed to monitor the performance of testing. Experiments were carried out by liquid-liquid extraction with ethyl acetate selected as an optimum extraction solvent for the estimation of both bupropion and its metabolite. Briefly, $100 \mu \mathrm{l}$ of $0.5 \mathrm{~N}$ sodium carbonate was added to $100 \mu \mathrm{l}$ of plasma and $50 \mu \mathrm{l}$ of internal standard dilution $(5 \mu \mathrm{g} / \mathrm{ml}$ diazepam solution) in a clean test tube. Sodium carbonate was added to the extraction buffer to maintain the drug and metabolite in un-ioned state. The mixture was vortexed for a minute, and $4 \mathrm{ml}$ extraction solution (ethyl acetate) was added to it followed by centrifugation at 4,000 rpm for 5 minutes. The organic layer $(3.5 \mathrm{ml})$ was removed and transferred to a fresh tube and mixed with $50 \mu \mathrm{l}$ of $0.1 \mathrm{~N} \mathrm{HCl}$. Supernatant was vortexed for 10 seconds and kept in an evaporator under nitrogen at $50^{\circ} \mathrm{C}$ for 10 minutes, and then reconstituted in $250 \mu \mathrm{l}$ diluent consisting of 80 parts of water and 20 parts of acetonitrile. Reconstituted solution was injected into LCMS for bupropion and hydroxy bupropion estimation. Six replicates of aqueous dilutions of bupropion, hydroxybupropion, and diazepam were injected and their peak response ratios were recorded to check the interferences or specificity. The calibration ranges for bupropion (1-500 ng/ml) and hydroxybupropion (5$2500 \mathrm{ng} / \mathrm{ml}$ ) were selected. Calibration curve was accepted if the back-calculated concentrations of minimum $75 \%$ of calibration standard (without including standard zero) were within $85 \%$ and $115 \%$ of the nominal concentration. Coefficient of correlation of linear regression $\left(\mathrm{r}^{2}\right)$ of calibration curve was 0.98. Six different batches of biological matrix (9204, 122412, 123892, 123852, 123202 and 122501) were analyzed for selectivity exercise. Six blank samples spiked with LLOQ (lower limit of quantification) were processed by sample preparation procedure. Peak area was evaluated at the retention time of analyte and internal standard. Selectivity was accepted only if the peak area in blank at retention time of analyte was $<20 \%$ of mean peak area of analyte at LLOQ and $<5 \%$ of mean peak of internal standard in calibration standard for internal standard. Long-term stability of analyte was evaluated using low and high QC samples stored below $-50^{\circ} \mathrm{C}$ in deep freezer for a period of 15 days. Six replicates of low and high quality control samples were used for each stability exercise. The stored QC samples were analyzed against freshly spiked calibration curve.

\section{Data analysis}

The population was categorized as poor and rapid metabolizers for the group of drugs metabolized by CYP2B6 on the basis of CYP2B6 activity. The enzyme activity was determined by evaluating hydroxybupropion/ bupropion ratio. The concentration of bupropion and hydroxybupropion was quantified from the blood samples drawn at pre-dose, $1 \mathrm{~h}$ post-dose, $3 \mathrm{~h}$ post-dose, $6 \mathrm{~h}$ post-dose and $10 \mathrm{~h}$ post-dose from the subjects kept inhouse till $10 \mathrm{~h}$ post-dose. Based on the concentration of the parent drug at the above mentioned time points, $t_{\max }$ (time to reach the drug at the highest concentration) of $3 \mathrm{~h}$ was selected for the evaluation of CYP2B6 activity. The frequency histogram was constructed with $\log$ (metabolite/drug at $t_{\max }$ ) versus the number of volunteers. The presence of different categories of individuals was indicated in frequency histogram if the frequency histogram was different from the normal distribution. On visual inspection of frequency histogram, approximate antimode position was established as the point on graph where two different modes are separated. However the exact antimode was derived by probit plot analysis. This is a graphical method in which standard deviates of a normal distribution are plotted against the $\log$ (metabolite/drug). Deviations from linearity in probit plots have been interpreted as existence of polymorphism. Scatter type chart was prepared with $\log$ (metabolite/drug) on $\mathrm{x}$-scale and probit on $\mathrm{y}$-scale. Trendlines were added to the plot to get best linear fit. Based on the selected trendline, a polynomial equation of regression was obtained. Intercept at $\mathrm{x}$ was the antimode. Individuals having log metabolite/drug ratio less than the antimode were classified as poor metabolizers. The mean of the ratio (metabolite/drug) of poor and rapid metabolizers was analyzed by student $t$-test to evaluate the significance of difference between poor and rapid metabolizers and the $P$ value of less than 0.05 was accepted as statistically significant.

\section{Results}

None of the volunteers reported any undesirable effect or adverse event during or after the study. No interference was observed in the retention time of bupropion or hydroxybupropion. The retention time of 1.16 (bupropion), 1.13 (hydroxybupropion), and $1.70 \mathrm{~min}$ (diazepam) was tuned. The sensitivity of estimation of bupropion and hydroxybupropion or percent coefficient variation at LLOQ was $6.59 \%$ and $6.87 \%$, respectively. The estimation procedure was specific as no interfering 
peak was observed in six different batches of biological matrix. The coefficient of correlation of linear regression (r) was 0.9982 for bupropion and 0.9982 for hydroxybupropion. Calibration curves of bupropion and hydroxybupropion are shown in Figure 1. Percent accuracy of the calibrators and quality control samples was between 85 and $115 \%$. Precision for bupropion and hydroxybupropion was estimated as mean \% CV (coefficient of variation). It was between 3.9 and $5.7 \%$ for all three levels of quality control samples. The values were within FDA defined limit of $<15 \%$. The frequency histogram and probit plot analysis described the bimodality of the studied population with respect to $\log$ (metabolite/drug ratio) (Figures 2 and 3). Regression analysis done on the probit plot yielded a best linear fit at $\mathrm{R}^{2}=0.938$. The trendline equation $\left(y=-3.318 x^{2}+3.747 x+1.429\right)$ was obtained. On solving the equation, intercept at $\mathrm{x}$-axis, which was actually an antimode, was found to be 0.5 [log (hydroxybupropion/bupropion)]. Individuals having log ratio of hydroxybupropion/bupropion $<0.5$ were categorized as poor metabolizers. Based on the antimode value, 20.56\% of population was categorized as poor metabolizer for the category of drugs metabolized by CYP2B6. Significant difference was observed between the mean ratio of metabolite/drug of rapid metabolizers $($ Mean $=0.59)$ and poor metabolizers $($ Mean $=0.26)$ with $\mathrm{P}<0.0001$ using student $t$-test (Table 2).

\section{Discussion}

This study reports the prevalence of poor and rapid metabolizers for the category of drugs metabolized by CYP2B6 in the target population. Interest in CYP2B6 has been developed by an ever-increasing list of substrates metabolized by this isoform as well as polymorphic and ethnic variations in the expression and activity of CYP2B6. Previous in vitro heterologous expression studies have shown that the polymorphism found in alleles CYP2B6"5, "6, "7, and "9 can alter the expression and/or activity of the enzyme (Ariyoshi et al. 2001; Iwasaki et al. 2004; Jinno et al. 2003). The functional significance of CYP2B6 variants has been shown for a variety of drugs. For example, in AIDS clinical studies, CYP2B6 variants have been associated with 2to 4-fold higher plasma EFV and NVP (Haas et al. 2004; Rotger et al. 2005; Rodriguez-Novoa et al. 2005; Tsuchiya et al. 2004) in HIV patients; $\geq 2$-fold higher plasma EFV concentration is associated with neuropsychological adverse effects (Haas et al. 2004; Rotger et al. 2005; Marzolini et al. 2001; Hasse et al. 2005). Besides the antiretroviral drugs, CYP2B6 variants have also been

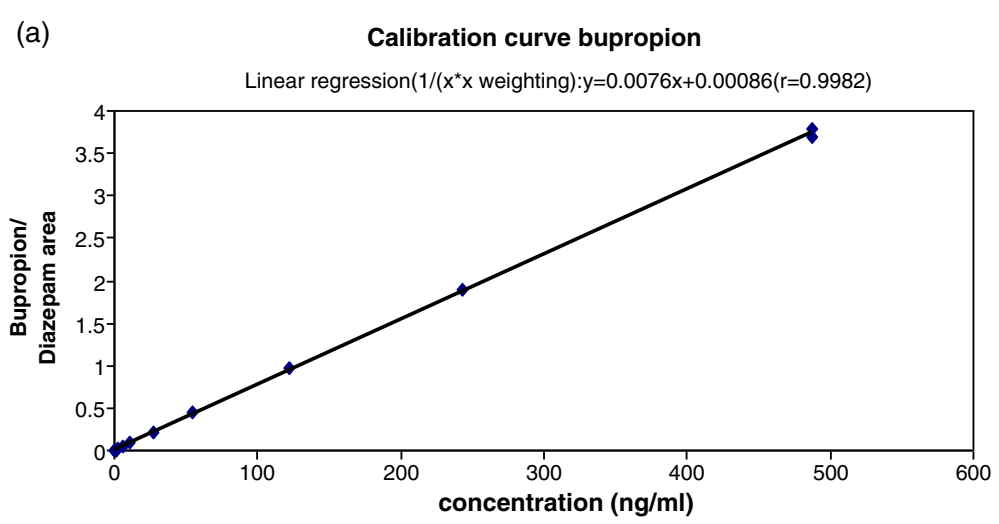

(b) Calibration curve hydroxybupropion

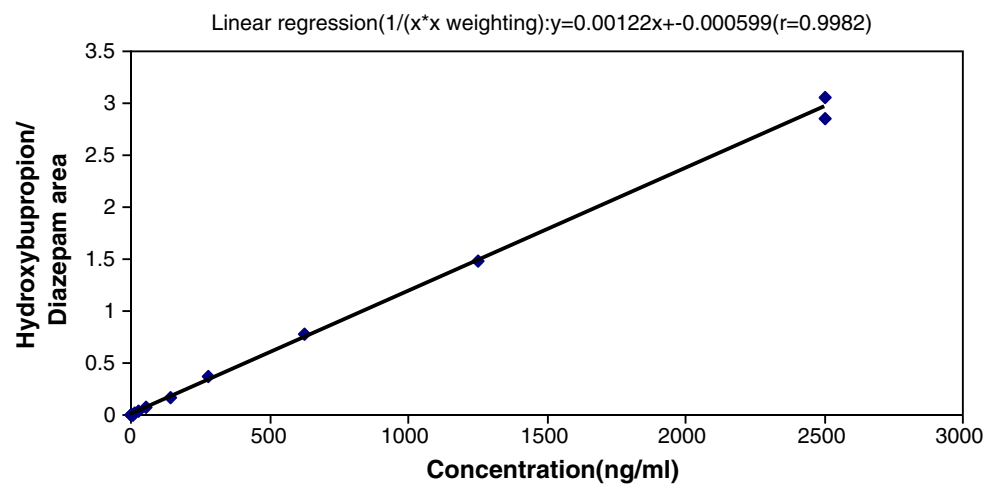

Figure 1 Calibration curves for the estimation of (a) bupropion, and (b) hydroxybupropion. 


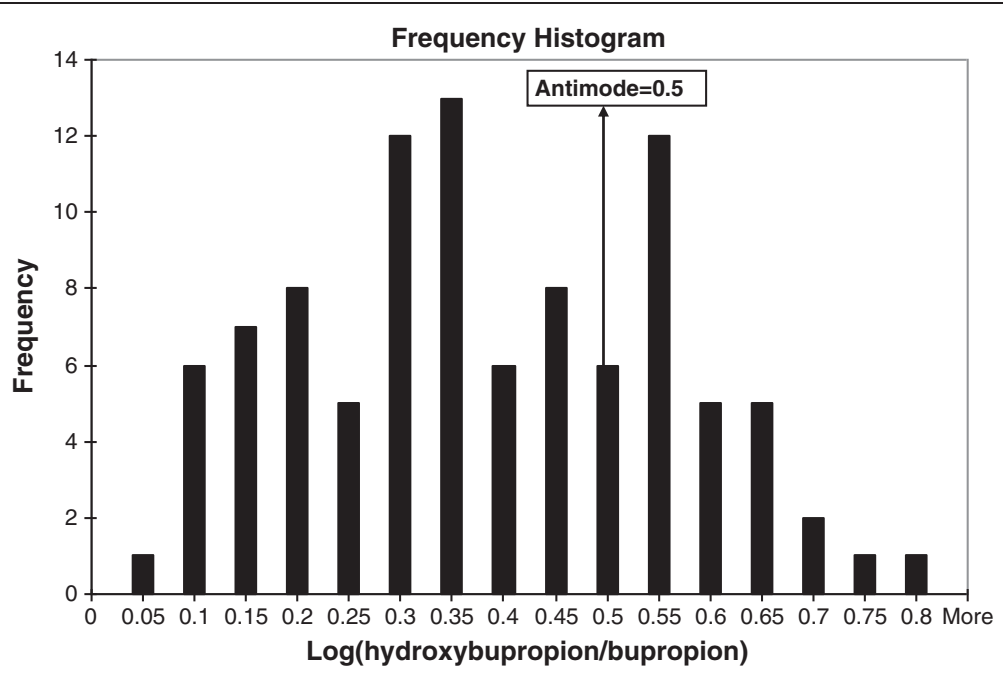

Figure 2 Frequency histogram plotted as log ratio of hydroxybupropion/bupropion vs. number of individuals. Arrow indicates antimode at 0.5 .

found to influence the metabolism and pharmacokinetics of bupropion (an antidepressant) (Hesse et al. 2004) and cyclophosphamide (an anticancer and immunosuppressive) (Xie et al. 2003). This study is the first attempt to identify poor and rapid metabolizers of the drugs metabolized by CYP2B6 in north Indian population residing in the national capital. Bupropion is widely used in phenotyping of CYP2B6 (Faucette et al. 2000; Kirchheiner et al. 2003; Rotger et al. 2007; Chung et al. 2011) and has been found to be a safe and tolerable drug. We did not report adverse effect of the drug during the clinical trial, and found it a safe, suitable and tolerable drug. Bupropion and its metabolites were measured in the plasma by LCMS/MS. Validation parameters were within the acceptable limits as recommended in FDA. Analysis of the results based on frequency histogram and probit analysis revealed that $20.56 \%$ of the target population was poor metabolizer. The prevalence of poor metabolizers, which we observed in this study, was comparatively lower than West Africa (54\%) (Malhotra et al. 2006), Papua New Guinea (63\%) (Malhotra et al. 2006), Spain (40\%) (Novoa et al. 2005), Mongolian (35.5\%) (Davalkham et al. 2009), Japanese (32.6\%) (Gatanaga et al. 2007), Han Chinese (32.9\%) (Guan et al. 2006), African American (54.6\%) (Klein et al. 2005), Ghanians (59.7\%) (Klein et al. 2005), Caucasians (38.9\%) (Blievernicht et al. 2007) and Koreans (23.9\%) (Klein et al. 2005). In India, percentage of poor metabolizers was $40 \%$ in South Indian population (Ramachandran et al. 2009). In comparison, North Indian population reported $20.56 \%$ poor metabolizers, which is considerably lower. The difference might be attributed to the life style and genetics of these two diverse groups of populations in India. In a study by Rendic (2002), nutrition has been reported to play an important role in drug metabolism and affect some of the CYP isoforms including 1A1, 1A2, 1B1, 2A6, 2B6, 2C8, 2C9, 2C19, 2D6, 3A4 and 3A5. Similarly, occupational exposure to hazardous chemicals is

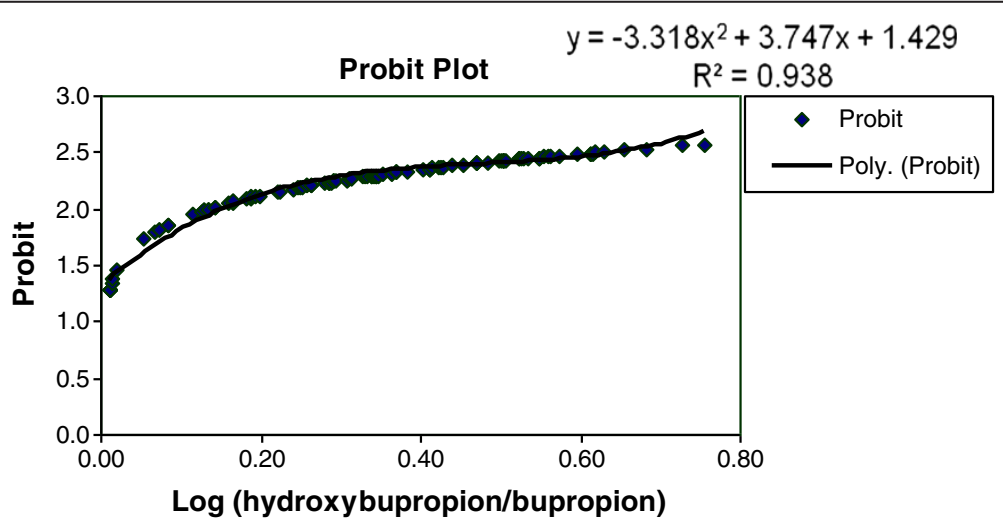

Figure 3 Probit plot of log (hydroxybupropion/bupropion) vs. probit. 
Table 2 Evaluation of mean ratio of poor and rapid metabolizers of CYP2B6 using $t$-test

\begin{tabular}{lll}
\hline Variables & $\begin{array}{l}\text { Poor } \\
\text { metabolizers }\end{array}$ & $\begin{array}{l}\text { Rapid } \\
\text { metabolizers }\end{array}$ \\
\hline Mean & 0.260093 & 0.590142 \\
\hline Variance & 0.022124 & 0.004614 \\
\hline $\begin{array}{l}\text { Hypothesized mean } \\
\text { difference }\end{array}$ & 0 & - \\
\hline Degree of freedom & 76 & - \\
\hline$t$ Statistics & -15.2236 & - \\
\hline $\mathrm{P}(\mathrm{T}<=t)$ one-tail & $4.34 \mathrm{E}-25$ & - \\
\hline$t$ Critical one-tail & 1.665151 & - \\
\hline
\end{tabular}

reported to affect CYP1A1 and CYP2E1 (Nan et al. 2001). In this study, we could not evaluate the correlation of phenotype with genotype, which would be advantageous to understand the genetic background of the difference in poor and rapid metabolizers. However, the prevalence of $20.56 \%$ of poor phenotype for CYP2B6 reported in this study cannot be ignored because of its involvement in the metabolism of drugs commonly used for the treatment of cancer, HIV infection and depression, where the treatment is usually long term, and these drugs may be toxic due to poor metabolism.

\section{Conclusion}

The antimode or cutoff defined in this study can be used as a tool for evaluating the status of CYP2B6 activity using bupropion as a probe drug. The baseline information would be clinically useful before administering the drugs metabolized by this isoform.

\section{Competing interests}

Authors declare that there is no competing interest.

\section{Authors' contributions}

EV did the experimental work in the study. SA and MT planned the study. NS was involved in getting the approval for conducting clinical trial in Ranbaxy Laboratories Limited. The statistical analysis was carried out by VS. SA was responsible for overall supervision and drafting the manuscript. All authors read and approved the final manuscript.

\section{Acknowledgements}

Authors thank all the study participants and recruiting team of Ranbaxy Laboratories Limited, India. The Department of Biochemistry acknowledges UGC SAP (DRS-1).

\section{Author details \\ 'Department of Biochemistry, Jamia Hamdard, Hamdard Nagar, New Delh 110062, India. ${ }^{2}$ Ranbaxy Clinical Pharmacology Unit, Ranbaxy Laboratories Limited, Gurgaon, India.}

Received: 21 July 2012 Accepted: 8 October 2012 Published: 16 October 2012

\section{References}

Adithan C, Gerard N, Vasu S, Rosemary J, Shashindran CH, Krishnamoorthy R (2003) Allele and genotype frequency of CYP2C19 in a Tamilian population. Brit J Clin Pharmacol 56:331-333
Anitha A, Banerjee M (2003) Arylamine N-acetyltransferase 2 polymorphism in the ethnic population of South Indians. Int J Mol Med 11:125-131

Ariyoshi N, Miyazaki M, Toide K, Sawamura Y, Kamataki T (2001) A single nucleotide polymorphism of CYP2B6 found in Japanese enhances catalytic activity by autoactivation. Biochem Biophys Res Commun 281:1256-1260

Blievernicht JK, Schaeffeler E, Klein K, Eichelbaum M, Schwab M, Zanger UM (2007) MALDI-TOF mass spectrometry for multiplex genotyping of CYP2B6 single-nucleotide polymorphisms. Clin Chem 53:124-133

Cho JY, Lim HS, Chung JY, Yu KS, Kim JR, Shin SG, Jang IJ (2004) Haplotypes structure and allele frequencies of CYP2B6 in a Korean population. Drug Metab Dispos 32:1341-1344

Chung JY, Cho JY, Lim HS, Kim JRYKS, Lim KS, Shin SG, Jang IJ (2011) Effects of pregnane $\mathrm{X}$ receptor (NR1/2) and CYP2B6 genetic polymorphisms on the induction of bupropion hydroxylation by rifampin. Drug Metab Dispos 39(1):92-97

Davalkham J, Hayashida T, Tsuchiya K, Gatanaga H, Nyamkhuu D, Oka S (2009) Allele and genotype frequencies of cytochrome P450 2B6 gene in a Mongolian population. Drug Metab Dispos 37:1991-1993

Erickson DA, Mather G, Trager WF, Levy RH, Keirns JJ (1999) Characterization of the in vitro biotransformation of the HIV-1 reverse transcriptase inhibitor nevirapine by human hepatic cytochromes P450. Drug Metab Dispos 27:1488-1495

Faucette SR, Hawke RL, Lecluyse EL, Shord SS, Yan B, Laethem RM, Lindley CM (2000) Validation of bupropion hydroxylation as a selective marker of human cytochrome P450 2B6 catalytic activity. Drug Metab Dispos 28:1222-1230

Gatanaga H, Hayashida T, Tsuchiya K, Yoshino M, Kuwahara T, Tsukada H, Fujimoto K, Sato I, Ueda M, Horiba M, Hamaguchi M, Yamamoto M, Takata N, Kimura A, Koike T, Gejyo F, Matsushita S, Shirasaka T, Kimura S, Oka S (2007) Successful efavirenz dose reduction in HIV type 1-infected individuals with cytochrome P450 B6*6 and *26. Clin Infect Dis 45:1230-1237

Guan S, Huang M, Li X, Chen X, Chan E, Zhou SF (2006) Intra and inter-ethnic differences in the allele frequencies of cytochrome P450 2B6 gene in Chinese. Pharm Res 23:1983-1990

Haas DW, Ribaudo HJ, Kim RB, Tierney C, Wilkinson GR, Gulick RM, Clifford DB, Hulgan T, Marzolini C, Acosta EP (2004) Pharmacogenetics of efavirenz and central nervous system side effects: An adult AIDS clinical trials group study. AIDS 18:2391-2400

Hasse B, Gunthard HF, Bleiber G, Krause M (2005) Efavirenz intoxication due to slow hepatic metabolism. Clin Infect Dis 40:22-23

Hesse LM, He P, Krishnaswamy S, Hao Q, Hogan K, von Moltke LL, Greenblatt DJ, Court MH (2004) Pharmacogenetic determinants of inter-individual variability in bupropion hydroxylation by cytochrome P450 2B6 in human liver microsomes. Pharmacogenetics 14:225-238

Hiratsuka M, Takekuma Y, Endo N, Narahara K, Hamdy SI, Kishikawa Y, Matsuura M, Agatsuma Y, Inoue T, Mizugaki M (2002) Allele and genotype frequencies of CYP2B6 and CYP3A5 in Japanese population. Eur J Clin Pharmacol 58:417-421

Hiratsuka M, Hinai Y, Konno Y, Nozawa H, Konno S, Mizugaki M (2004) Three novel single nucleotide polymorphism (SNPs) of the CYP2B6 gene in Japanese individuals. Drug Metab Pharmcokin 19(2):155-158

Iwasaki M, Yoshimura Y, Asahi S, Saito K, Sakai S, Morita S et al (2004) Functional characterization of single nucleotide polymorphisms with amino acid substitution in CYP1A2, CYP2A6, and CYP2B6 found in the Japanese population. Drug Metab Pharmacokinet 19:444-452

Jinno H, Tanaka-Kagawa T, Ohno A, Makino Y, Matsushima E, Hanioka N, Ando M (2003) Functional characterization of cytochrome P450 2B6 allelic variants. Drug Metab Dispos 31:398-403

Kirchheiner J, Klein C, Meineke I, Sasse J, Zanger UM, Murdter TE, Roots I, Brockmoller J (2003) Bupropion and hydroxylbupropion pharmacokinetics in relation to genetic polymorphism in CYP2B6. Pharmacogenetics 13:619-626

Klein K, Lang T, Saussel T, Barbosa Sicard E, Schunck WH, Elichelbaum M, Schwab M, Zanger UM (2005) Genetic variability of CYP2B6 in population of African and Asian origin: Allele frequencies, novel functional variant and possible implication for anti HIV therapy with efavirenz. Pharmacogenet Genomics 15:861-873

Kumar V, Singh S, Yadav CS (2010) Ahmed (2010) CYP1A1 and CYP3A4 polymorphic variations in Delhi population of Northern India. Environ Toxicol Pharmacol 29(2):126-130 
Lamba V, Lamba JK, Dilawari JB, Kohli KK (1998a) Genetic polymorphism of CYP2D6 in North Indian subjects. Eur J Clin Pharmacol 54:787-791

Lamba JK, Dhiman RK, Kohli KK (1998b) Genetic polymorphism of the hepatic cytochrome P450 2C19 in North Indian subjects. Clin Pharmacol Ther 63(4):422-427

Lamba V, Lamba J, Yasuda K, Strom S, Davila J, Hancock ML, Fackenthal JD Rogan PK, Ring B, Wrington SA, Schuetz EG (2003) Hepatic CYP2B6 expression: Gender and ethnic differences and relationship to CYP2B6 genotype and CAR (Constitutive Androstane Receptor) expression. Clin Pharmacol Ther 307:906-922

Lang T, Klein K, Richter T, Zibat A, Kerb R, Eichelbaum M, Schwab M, Zanger UM (2001) Extensive genetic polymorphism in the human CYP2B6 with impact on expression and function in human liver. Pharmacogenetics 11:399-415

Malhotra RK, Ziats MN, Bockarie MJ, Zimmerman PA (2006) Prevalence of CYP2B6 alleles in malaria-endemic populations of West Africa and Papua New Guinea. Eur J Clin Pharmacol 2:267-275

Marzolini C, Telenti A, Decosterd LA, Greub G, Biollaz J, Buclin T (2001) Efavirenz plasma levels can predict treatment failure and central nervous system side effects in HIV-1-infected patients. AIDS 15:71-75

Mehlotra RK, Ziats MN, Bockarie MJ, Zimmerman PA (2006) Prevalence of CYP2B6 allele in malaria-endemic populations of West Africa and Papua New Guinea. Eur J Clin Pharmacol 62(4):267-275

Nan HM, Kim H, Lim HS, Choi JK, Kawamoto T, Kang JW, Lee CH, Kim YD, Kwon EH (2001) Effects of occupation, lifestyle and genetic polymorphisms of CYP1A1, CYP2E1, GSTM1 and GSTT1 on urinary 1-hydroxypyrene and 2-naphthol concentrations. Carcinogenesis 22(5):787-793

Novoa SR, Barreiro P, Rendon A, Nacher IJ, Lahoz JG, Soriano V (2005) Influence of $516 \mathrm{G} \rightarrow T$ polymorphisms at the gene encoding the CYP450-2B6 isoenzyme on efavirenz plasma concentrations in HIV-infected subjects. Clin Infect Dis 40:1358-1361

Ramachandran G, Kumar AKH, Rajasekaran S, Kumar P, Ramesh K, Anitha S, Narendran G, Menon P, Gomathi C, Swaminathan S (2009) CYP2B6 G516T polymorphism but not rifampin co administration influences steady-state pharmacokinetics of efavirenz in human immunodeficiency virus-infected patients in South India. Antimicrob Agents Chemother 53(3):863-868

Rendic S (2002) Summary of information on human CYP enzymes: human P450 metabolism data. Drug Metab Rev 34:83-448

Rodriguez-Novoa S, Barreiro P, Rendon A, Jimenez-Nacher I, Gonzalez-Lahoz J, Soriano V (2005) Influence of 516G>T polymorphisms at the gene encoding the CYP450 2B6 isoenzyme on efavirenz plasma concentrations in HIV-infected subjects. Clin Infect Dis 40:1358-1361

Rotger M, Colombo S, Furrer H, Bleiber G, Buclin T, Lee BL, Keiser O, Biollaz J, Decosterd L, Telenti A (2005) Swiss HIV cohort study: Influence of CYP2B6 polymorphism on plasma and intracellular concentrations and toxicity of efavirenz and nevirapine in HIV-infected patients. Pharmacogenet Genomics $15: 1-5$

Rotger M, Tegude H, Colombo S, Cavassini M, Furrer H, Decosterd L, Blievernicht J, Saussele T, Gunthard HF, Schwab M, Eichelbaum M, Telenti A, Zanger UM (2007) Predictive value of known and novel alleles of CYP2B6 for efavirenz plasma concentration in HIV-infective individuals. Clin Pharmacol Ther 81:557-566

Simonsson US, Jansson B, Hai TN, Huong DX, Tybring G, Ashton M (2003) Artemisinin auto induction is caused by involvement of cytochrome P450 $2 \mathrm{~B} 6$ but not 2C9. Clin Pharmacol Ther 74:32-43

Solus JF, Arietta BJ, Harris JR, Sexton DP, Steward JQ, Mc Munn C, Ihrie P, Mehall JM, Edwards TL, Dawson EP (2004) Genetic variation in eleven phase I drug metabolism genes in an ethnically diverse population. Pharmacogenomics 5:895-931

Tsuchiya K, Gatanaga H, Tachikawa N, Teruya K, Kikuchi Y, Yoshino M, Kuwahara T, Shirasaka T, Kimura S, Oka S (2004) Homozygous CYP2B6*6 (Q172H and K262R) correlates with high plasma efavirenz concentrations in HIV-1 patients treated with standard efavirenz-containing regimens. Biochem Biophys Res Commun 319:1322-1326

Wang H, Thompkins LM (2008) CYP2B6: New insights into a historically overlooked cytochrome P450 isozyme. Curr Drug Metab 9:598-610

Ward BA, Gorski JC, Jones DR, Hall SD, Flockhart DA, Desta Z (2003) The cytochrome P450 2B6 (CYP2B6) is the main catalyst of efavirenz primary and secondary metabolism: Implication for HIV/AIDS therapy and utility of efavirenz as a substrate marker of CYP2B6 catalytic activity. J Pharmacol Exp Ther 306:287-300
Xie HJ, Yasar U, Lundgren S, Griskevicius L, Terelius Y, Hassan M, Rane A (2003) Role of polymorphic human CYP2B6 in cyclophosphamide bioactivation. Pharmacogenomics J 3:53-61

Zukunft J, Richter T, Hirsch-Ernst KL, Nussler AK, Klein K, Schwab M, Eichelbaum M, Zanger UM (2005) A natural CYP2B6 TATA box polymorphism (82T $\rightarrow$ C) leading to enhanced transcription and relocation of the transcriptional start site. Mol Pharmacol 67(5):1772-178

doi:10.1186/2193-1801-1-34

Cite this article as: Varshney et al:: Prevalence of poor and rapid metabolizers of drugs metabolized by CYP2B6 in North Indian population residing in Indian national capital territory. SpringerPlus 2012 $1: 34$.

\section{Submit your manuscript to a SpringerOpen ${ }^{\odot}$ journal and benefit from:}

- Convenient online submission

- Rigorous peer review

- Immediate publication on acceptance

- Open access: articles freely available online

- High visibility within the field

- Retaining the copyright to your article

Submit your next manuscript at $>$ springeropen.com 